\title{
Arresting Early Childhood Caries with Silver Diamine Fluoride-A Literature Review
}

\author{
Marcus HT Fung, May CM Wong, Edward CM Lo and CH Chu*
}

Department of Dentistry, The University of Hong Kong, 1B30, Prince Philip Dental Hospital, 34 Hospital Road, Hong Kong SAR

\begin{abstract}
Conventional restorative management of early childhood caries (ECC) is unlikely to tackle this prevalent disease, and arresting caries treatment using silver diamine fluoride (SDF) has become a pragmatic strategy, particularly for young and apprehensive children. Arrested caries is clinically characterized by its increase in hardness and a dark brown to black coloration. Subsequent restorative procedures can be carried out if necessary. This review article discusses the rationale of arresting caries treatment, mechanism of action of SDF, and safety and complications of SDF treatment. A literature search using PubMed was performed to review the clinical trials using SDF to manage ECC. Results found 6 clinical trials published in English since 1980. The studies suggested that one-off application of $12 \%$ SDF is not effective in arresting caries in children, but $38 \%$ SDF is. The main disadvantage of SDF treatment is black staining of the arrested lesion, but significant complications were not reported. In general, the studies concluded that topical application of SDF is a simple and low cost method to arrest ECC. This treatment strategy therefore increases access for children in developing countries to receive affordable dental treatment.
\end{abstract}

Keywords: Early childhood caries, Review, Arrested caries, Silver diamine fluoride

\section{Introduction}

Early childhood caries (ECC) has been regarded as one of the most prevalent chronic diseases in early childhood. Many studies show ECC was often neglected and most of the decay was left untreated [1]. Early treatment of ECC is important because untreated caries can lead to pain, sepsis and spreading infection, malnutrition due to the inability to eat, and poor general health. Children with severe ECC or those who are not able to cooperate well for traditional restorative treatment often require general anaesthesia [2]. The cost of dental care is high.

The traditional way to manage ECC involves surgical removal of all the infected and softened dental tissue followed by the filling of the cavity to restore the function and aesthetics of the tooth [1]. With better understanding of caries pathology and evidence from clinical trials, it is generally accepted that arresting caries treatment can effectively prevent caries from progressing. Some researchers and dentists proposed a paradigm shift from surgical to non-surgical caries management in children [3]. In addition, managing ECC by conventional restorative methods alone is insufficient at tackling this prevalent disease, particularly when dental equipment and manpower are not readily available in disadvantaged communities or developing countries.

Children, in particular those who are young or apprehensive, are not able to cooperate for lengthy, complex restorative procedures. Children who are from disadvantaged families cannot afford the cost of restorative treatment. Therefore, in recent decades, arresting caries treatment has gained more and more attention in community dental care to stop caries from progressing. Although the dental aesthetics is not pleasing, children with arrested caries will at least be less susceptible to suffering from pain and infection. More complex procedures can be carried out when children are cooperative enough or when the resources are available. This also facilitates access to dental care for children in developing countries.

There are various methods proposed to arrest dental caries in children, such as xylitol gum chewing and the use of fluoridated agents. These methods in general do not require complex equipment and can be carried out in non-clinical environments. Fluoride can be self-applied at home or at school, or professionally applied at a higher fluoride concentration by dental professionals. Among these caries arresting methods, topical application of silver diamine fluoride (SDF) has been receiving more and more attention due to its low cost and simplicity in treatment. The advantages of caries treatment with SDF include its attributes of pain and infection control, ease of use, low material costs, non-invasive nature of the treatment procedure, and minimal requirement for personnel time and training. A recent systematic review concluded that SDF treatment may fulfil the World Health Organization (WHO) Millennium Goals and the United States Institute of Medicine's criteria for $21^{\text {st }}$ century medical care [4]. SDF treatment can potentially increase access to care, improve oral health, and reduce the need for emergency care and treatment [4]. This review article discusses the rationale of arresting caries treatment, mechanism of action of SDF, and safety and complications of SDF treatment in children. A literature search using Pubmed was performed to review the clinical trials using SDF to manage ECC.

\section{Rationale for arresting caries in children}

The purpose of arresting caries treatment is to halt or slow down caries progression in order to minimize children's discomfort and potential pulpal damage. Dental caries occurs when demineralisation outweighs remineralisation, resulting in net loss of tooth minerals [5]. In addition to demineralisation, dental caries also involves the

*Corresponding author: Department of Dentistry, The University of Hong Kong, 1B30, Prince Philip Dental Hospital, 34 Hospital Road, Hong Kong SAR, Tel: +852 2859 0287; Fax: +852 2858 2532; E-mail: chchu@hku.hk

Received November 08, 2013; Accepted December 17, 2013; Published December 24, 2013

Citation: Fung MHT, Wong MCM, Lo ECM, Chu CH (2013) Arresting Early Childhood Caries with Silver Diamine Fluoride-A Literature Review. Oral Hyg Health 1: 117. doi: 10.4172/2332-0702.1000117

Copyright: (c) 2013 Fung MHT, et al. This is an open-access article distributed under the terms of the Creative Commons Attribution License, which permits unrestricted use, distribution, and reproduction in any medium, provided the original author and source are credited. 
breakdown of collagen fibres. Once caries progresses through the highly mineralized enamel to the underlying dentine, destruction spreads laterally and pulpally.

Conventional caries treatment involves removal of all infected dentine together with demineralised dentine because it has long been accepted that demineralised dentine cannot regain its structure. In an acidic environment, calcium and phosphate are lost from the mineralised dental tissue. However, it is important to note that dental caries is a dynamic process. Therefore, it can, theoretically, be arrested at any stage, even in the presence of cavitations [6,7]. Subsequent studies have shown that two layers of dentine lesion with distinct microscopic and chemical structure can be identified $[8,9]$. The outer dentine layer is called the infected layer because it is infected with bacteria. The inner dentine layer is called the affected layer because the dentine is softened (affected) by plaque acid but scarcely infected with bacteria. This affected dentine layer still contains a high concentration of mineral salts and, thus, can be re-mineralised if the surrounding conditions are favourable for mineralisation [7]. When dentinal tubules in the area between the soft and hard dentine are obstructed with large mineral crystals, dental caries can be arrested [8].

Arrested dentine caries is clinically characterized by its increase in hardness and a dark brown to black coloration [5]. Clinical studies show that carries in primary teeth can be arrested by chewing xylitol chewing gum [10], brushing with fluoride toothpaste [11], or having fluoridated agents professionally applied, such as fluoride varnish [12] and SDF [12-14], or sealing cavities with fluoride-releasing glass ionomer cement $[13,15]$. In vitro studies also show that the surface layer of the arrested lesion contains a high mineral content. An arrested carious lesion is less permeable, more resistant to acid dissolution, of high $\mathrm{pH}$ value, and displays less enzyme activities when comparing with active caries [16]. Also, histopathological studies in arrested carious lesions in primary teeth reveal a significantly more favourable pulpal status than active caries $[17,18]$. These studies suggest that arresting caries treatment can be a conservative treatment option in managing dentine caries in primary teeth.

\section{Mechanism of action of SDF}

The exact mechanism of SDF is not understood. Yamaga and his co-workers suggest that both fluoride ions and silver ions contribute to its mechanism of action [19]. They propose that fluoride ions act mainly on tooth structure while silver ions act mainly on cariogenic bacteria. SDF reacts with hydroxyapatite $\left[\mathrm{Ca}_{10}\left(\mathrm{PO}_{4}\right)_{6}(\mathrm{OH})_{2}\right]$ in an alkaline environment to form calcium fluoride $\left(\mathrm{CaF}_{2}\right)$ and silver phosphate $\left(\mathrm{Ag}_{3} \mathrm{PO}_{4}\right)$ as major reaction products. $\mathrm{CaF}_{2}$ provides sufficient fluoride for the formation of fluoroapatite $\left[\mathrm{Ca}_{10}\left(\mathrm{PO}_{4}\right)_{6} \mathrm{~F}_{2}\right]$, which is less soluble than hydroxyl apatite in an acidic environment.

The precipitated $\mathrm{Ag}_{3} \mathrm{PO}_{4}$ forms an insoluble layer over the tooth surfaceandacts as a phosphate ions reservoir to facilitate the transformation of hydroxyapatite to fluoroapatite [20]. The overall reaction can be summarized by the following equation:

$$
\mathrm{Ca}_{10}\left(\mathrm{PO}_{4}\right)_{6}(\mathrm{OH})_{2}+\mathrm{Ag}\left(\mathrm{NH}_{3}\right)_{2} \mathrm{~F} \rightarrow \mathrm{CaF}_{2}+\mathrm{Ag}_{3} \mathrm{PO}_{4}+\mathrm{NH}_{4} \mathrm{OH}
$$

Mei and her co-workers found that SDF provides an alkaline environment to render $\mathrm{CaF}_{2}$ less soluble and, therefore, serves as a fluoride reservoir for acid challenges by cariogenic bacteria [21]. In vitro studies show that SDF can inhibit demineralisation of hydroxyl apatite and preserve collagen from degradation in demineralised dentine tissue $[21,22]$. In addition, collagen breakdown of dentine was significantly reduced [23], and dentine hardness was significantly increased after SDF application [22].

SDF also has antibacterial properties. Silver ions can bind with negatively charged peptidoglycans in bacterial cell walls and disrupt membrane transport function, which in turn leads to cellular distortions and loss of viability [24]. Binding to sulphydryl groups (thio group of cystine), which is essential for enzyme activities [25], can inhibit bacterial enzyme activities, disrupt metabolic processes, and eventually cause death of the microbe [26]. This was demonstrated by the inhibition of plaque formation on enamel and dextran-induced agglutination of Streptococcus mutans [20,25]. Silver ions can oxidize thiol groups and, therefore, reduce acidogenicity of dental plaque [27] Moreover, silver ions inhibit bacterial DNA replications by attaching to guanine [28]. In vitro studies show that silver ions can inhibit adherence of carcinogenic bacteria to enamel surfaces [29], formation of Streptococcus mutans biofilm [30], and growth of Streptococcus mutans and Lactobacilli acidophilus [31].

\section{Safety and adverse effects of SDF}

A literature search found that there were no reported cases about acute toxicity or significant adverse effects after professional application of SDF. It is plausible that there is a minimal chance of excess silver accumulation causing toxicity because only a minute amount of SDF is applied to the dental tissue semi-annually or annually. Previous studies suggest that SDF did not cause severe pulpal reactions, and no severe pulpal damages have been reported [12,32]. An ex vivo study shows that over $90 \%$ of the deep carious primary teeth treated with SDF showed favourable pulpal response histologically, which was evidenced by the presence of abundant reparative dentine and a wide odontoblast layer [33].

Mild but transient gingival irritation can occur in the gingival margin after SDF application. There may also be presence of a small, white lesion intheoral mucosa, but generally it will heal spontaneously within two days $[12,32,34,35]$. Prevention by applying Vaseline over the gingival margin was proposed to prevent soft tissue irritation [36] SDF can leave behind a black stain that may last a few weeks. Therefore, it is important to ask the children not to spit or rub the saliva over their face after SDF application. Furthermore, measures should be available to prevent accidental spillage onto the clothes or skin of the children. The brown or black staining can be permanent. Although contact dermatitis was reported after sodium fluoride varnish application [37], so far, no such condition was reported after SDF application.

The 38\% SDF contains 44,800 ppm fluoride. Dental fluorosis could be a hypothetical risk for children due to the high concentration of fluoride ions. In vitro studies show that application of $4 \%$ silver fluoride (AgF) $(6,000 \mathrm{ppm} F)$ could induce fluorosis in rats [38]. In a solution containing $40 \% \mathrm{AgF}(60,000 \mathrm{ppm} \mathrm{F})$, the fluoride ions could enter the pulp through dentine to systemic circulation and result in fluorosis $[39,40]$. However, an ex vivo study did not support the passage of a significant amount of fluoride from dentine to dental pulp [41]. In the report of an investigation on AgF by the Dental Service of the Health Department of Western Australia, it concluded that there was insufficient evidence to support that the proper use of $\mathrm{AgF}$ in children would cause fluorosis [42].

Another concern about AgF solution was its unstable concentration of fluoride. A study, which can use up to double the expected concentration in some samples, might increase the possibility of toxicity 
[43]. In the presence of ammonia, the fluoride ions' concentration in the SDF is more stable than AgF's [21]. The average dosage of SDF applied with a micro-applicator was $0.22 \mathrm{mg}(8.8 \mu \mathrm{g} \mathrm{F})$ [21]. Therefore, the amount of SDF applied, even on several carious teeth, is far from reaching the acute toxic levels. A recent study in adults found that the serum concentrations of silver and fluoride ions after SDF application were of little risk of toxicity [44], but a similar study on children is not available.

The most common reported adverse effect of SDF is black staining of carious enamel and dentine, but not sound tooth tissue [12,14,32]. SDF stains carious dentine black permanently, particularly when higher concentrations or repeated application of SDF are applied [14]. The dark staining could be due to the formation of silver phosphate [14]. This may limit its clinical use in aesthetically demanding patients, particularly over the upper anterior teeth facial surfaces, which are common sites for ECC. Several ways were tried to reduce the black staining due to silver phosphate, but none were effective. An in vitro study tried application of potassium iodide after SDF in the hope that whitish silver iodide will form. However, silver iodide is photosensitive and turns brown or black upon exposure to light [19]. In addition, silver iodide has not been tested for its efficacy in preventing and arresting caries. Ammonium hexafluorosilicate has been developed to eliminate silver and its discoloration effect, but it was found to be significantly less efficacious than SDF $[45,46]$.

\section{SDF in prevention and arresting early childhood caries}

SDF has been used in Japan for prevention and arresting caries in children since the 1960s [19]. SDF is also used in other countries such as Australia, China, Cuba, and Nepal [12-14,32,33,47,48]. Studies suggested that SDF is effective in preventing new caries and arresting caries both in primary teeth and permanent teeth [12-15,32,33,47-50]. A recent systematic review concluded that topical application of SDF is more effective in caries prevention than fluoride varnish [4].

SDF is a colourless solution that can be applied on a tooth surface with a tiny applicator or brush. The concentration of SDF in commercial preparations varied from $3.8 \%$ to $38 \%$ (Table 1 ). The $3.8 \%$ preparation is specifically formulated for root canal treatment. For the use of prevention and arresting caries, the concentrations available varied from $10 \%$ to $38 \%$. As SDF can be applied without the need for complicated tools and equipment, this allows treatment for children by allied staffs under supervision in non-clinical environments, like outreach services in kindergartens.

A literature search of clinical trials using SDF to manage ECC in children was performed. The database used was PubMed and inclusion criteria were 1) clinical trials 2) published in the English language 3) since 1980. The search keywords were, silver fluoride OR diamine silver fluoride OR silver diamine fluoride AND clinical trial AND children. The search found 20 publications (Figure 1). The title and abstract of these 20 publications were screened; and 14 publications were excluded because they were not clinical trials or studies on permanent teeth. Full texts of the remaining 6 publications were assessed, and they are all included in this review.

Table 2 summarizes the main findings of the clinical trials in arresting dentine caries in primary teeth with silver diamine fluoride. Although the study performed by McDonald and Sheiham could not find significant caries arrested using a combination of SDF and stannous fluoride application on carious teeth of children [51], the

\begin{tabular}{|l|l|l|}
\hline Product (Concentration) & Manufacturer & Country \\
\hline Saforide 3.8\% RC & Toyo Seiyaku Kasei Co. Ltd. & Japan \\
\hline Saforide 38\% & Toyo Seiyaku Kasei Co. Ltd. & Japan \\
\hline Cariostatic (10\%) & InodonLabratorio & Brazil \\
\hline Cariestop(12\%) & BiodinamicaQuimica e FarmaceuticaLtda & Brazil \\
\hline Cariestop(30\%) & BiodinamicaQuimica e FarmaceuticaLtda & Brazil \\
\hline Bioride(38\%) & Densplylndustria e ComericioLtda & Brazil \\
\hline Fluoroplat(38\%) & LaboratoriosNaf & Argentina \\
\hline
\end{tabular}

Table 1: Commercially available silver diamine fluoride solutions presentation.

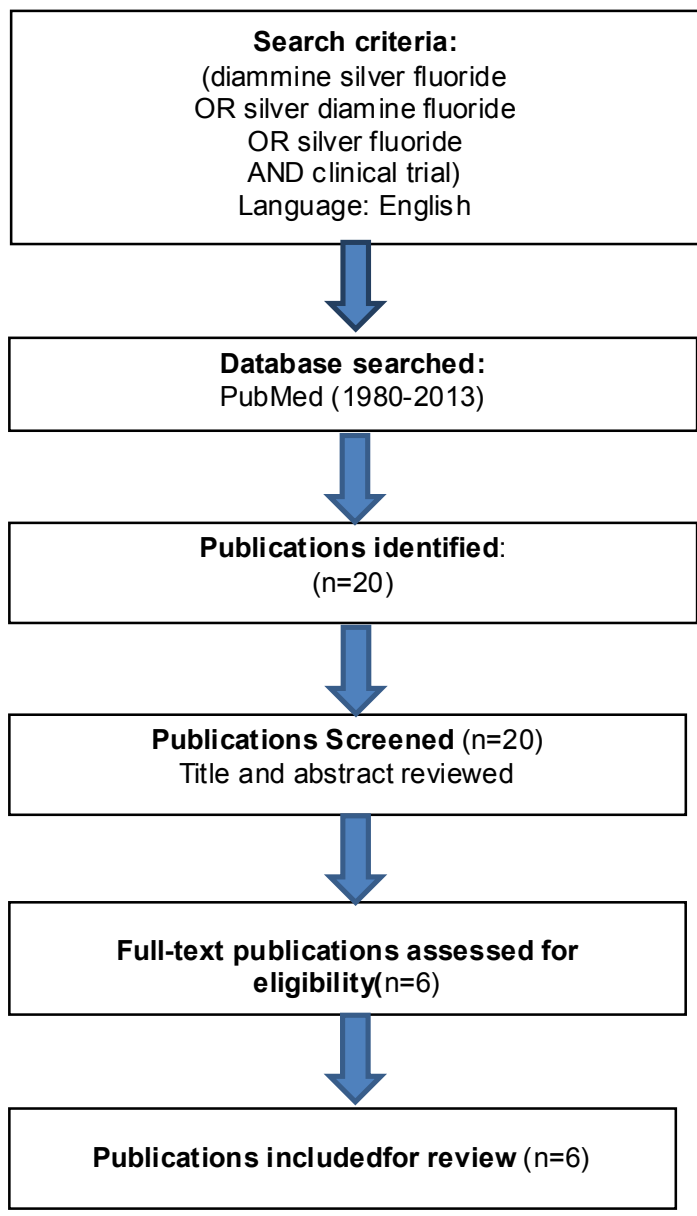

Figure 1: Flowchart of literature search of clinical trials of silver diamine fluorideto arrest caries in primary teeth.

other 5 studies, in general, reported that SDF is effective in arresting dentine caries in primary teeth. Chu and his co-workers found that annual application of $38 \%$ SDF is more efficacious in arresting caries in primary anterior teeth when compared with the application of $5 \%$ sodium fluoride varnish every 3 months [12]. They also found caries removal before SDF application had no significant effect in arresting caries. Several modifications in SDF application, such as changing the annual to biannual application and reducing the $38 \%$ to $12 \%$ SDF, were tested. Yee and his co-workers found that adding tannic acid, a reducing agent, could not enhance the arresting effect on caries [14]. While their findings support the effectiveness of 38\% SDF in arresting caries, they found one-off application of SDF at reduced concentration (12\%) could not arrest caries. 
Citation: Fung MHT, Wong MCM, Lo ECM, Chu CH (2013) Arresting Early Childhood Caries with Silver Diamine Fluoride-A Literature Review. Oral Hyg Health 1: 117. doi: 10.4172/2332-0702.1000117

Page 4 of 5

\begin{tabular}{|c|c|c|c|}
\hline Studies [Ref] (Site) & No. of teeth/ children (Age) & Intervention / Duration & Main results / Findings \\
\hline $\begin{array}{l}\text { McDonald and Sheiham } \\
\text { [51] (London, } \\
\text { England) }\end{array}$ & $\begin{array}{l}191 \text { carious lesions in } 52 \\
\text { children, } \\
\text { ( } 2 \text { to } 9 \text { years old, mean age }=5 \\
\text { years) }\end{array}$ & $\begin{array}{l}\text { Gp1-SnF2 } \\
\text { Gp2-SDF/SnF2 } \\
\text { Gp3-Control } \\
\text { Gp4-Minimal preparation+SDF/SnF2 + composite } \\
\text { Gp 5-Minimally preparation+composite } \\
\text { (Duration: } 18 \text { months) }\end{array}$ & $\begin{array}{l}\text { \% of carious lesions with progression: } \\
\text { Gp } 1: 46.5 \% \text {, } \\
\text { Gp 2:26.6\%, } \\
\text { Gp } 3: 53.0 \% \text {, } \\
\text { Gp } 4: 5.2 \% \\
\text { Gp } 5: 11.1 \%\end{array}$ \\
\hline $\begin{array}{l}\text { Gotjamanos et al. [33] } \\
\text { (Western Australia, } \\
\text { Australia) }\end{array}$ & $\begin{array}{l}55 \text { carious primary teeth } \\
(6 \text { to } 13 \text { years old, mean age }=9 \\
\text { years })\end{array}$ & $\begin{array}{l}\text { Application of } 40 \% \mathrm{AgF} \text { to residual caries followed by } \\
\text { atraumatic glass ionomer restorative restoration } \\
\text { Duration: } 3-56 \text { months (mean=16 months) }\end{array}$ & $\begin{array}{l}\text { Favorable pulpal response in } 50 \text { teeth }(91 \%) \text {. } \\
\text { Histological examination revealed abundant } \\
\text { reparative dentine and a wide odontoblast layer. }\end{array}$ \\
\hline $\begin{array}{l}\text { Chu et al. [12] } \\
\text { (Guangzhou, China) }\end{array}$ & $\begin{array}{l}375 \text { children } \\
(3 \text { to } 5 \text { years old, mean age }=4 \\
\text { years })\end{array}$ & $\begin{array}{l}\text { Gp1-Remove caries then annual SDF } \\
\text { Gp2 -Annual SDF } \\
\text { Gp3-Remove caries then NaF every 3months } \\
\text { Gp4-NaF every 3months } \\
\text { Gp5-Water (control) } \\
\text { Duration:30 months }\end{array}$ & $\begin{array}{l}\text { Mean no. of arrested carious surfaces: } \\
\text { Gp } 1: 2.5 \\
\text { Gp } 2: 2.8 \\
\text { Gp } 3: 1.5 \\
\text { Gp } 4: 1.5 \\
\text { Gp } 5: 1.3\end{array}$ \\
\hline $\begin{array}{l}\text { Llodra et al. [32] } \\
\text { (Santiago, } \\
\text { Cuba) }\end{array}$ & $\begin{array}{l}425 \text { children, } \\
\text { (around } 6 \text { yearsold) }\end{array}$ & $\begin{array}{l}\text { Gp1-Biannual SDF } \\
\text { Gp2-Control } \\
\text { Duration: } 36 \text { months }\end{array}$ & $\begin{array}{l}\text { Mean no. of arrested caries surfaces } \\
\text { Gp1:2.8, } \\
\text { Gp2:1.8. }\end{array}$ \\
\hline $\begin{array}{l}\text { Yee et al. [14] } \\
\text { (Kathmandu, Nepal) }\end{array}$ & $\begin{array}{l}976 \text { children, } \\
(3 \text { to } 9 \text { years old, } \\
\text { mean age }=5 \text { years })\end{array}$ & $\begin{array}{l}\text { Gp1-one-off } 38 \% \text { SDF }+ \text { Tannic acid } \\
\text { Gp2-one-off } 38 \% \text { SDF } \\
\text { Gp3-one-off } 12 \% \text { SDF } \\
\text { Gp4-control } \\
\text { Duration: } 24 \text { months }\end{array}$ & $\begin{array}{l}\text { Mean no. of arrested carious surfaces: } \\
\text { Gp1:2.2, } \\
\text { Gp 2:2.1, } \\
\text { Gp 3:1.5, } \\
\text { Gp 4:1.0 }\end{array}$ \\
\hline $\begin{array}{l}\text { Zhi et al. [13] } \\
\text { (Guangzhou, China) }\end{array}$ & $\begin{array}{l}212 \text { children } \\
\text { aged } 3 \text { to } 4 \text { years old (mean } \\
\text { age } 3.8 \text { years) }\end{array}$ & $\begin{array}{l}\text { Gp1-Annual 38\% SDF } \\
\text { Gp2-Biannual 38\% SDF } \\
\text { Gp3-Annual low viscosity glass ionomer } \\
\text { Duration:24 months }\end{array}$ & $\begin{array}{l}\% \text { of caries arrested: } \\
\text { Gp 1:79\%, } \\
\text { Gp } 2: 91 \% \\
\text { Gp } 3: 82 \%\end{array}$ \\
\hline
\end{tabular}

Table 2: Clinical trials using silver diamine fluoride to arrest caries in primary teeth.

Different application frequencies were reported in the literature, including one-off application [14], intense application several times at 2-3 days intervals [19], semi-annually [32], and annually [12]. Yee and her co-workers found that caries reversal can occur after a single application [14]. In addition, Zhi and her co-workers found that the caries arrest rate of $38 \%$ SDF was higher with biannual application than with annual application [13]. Llodra and his co-workers used biannual application of $38 \%$ SDF and also observed significant caries arrested on primary molars of children [32].

Gotjamanos performed SDF application followed by restoration with glass ionomer cement on 55 carious lesions on primary teeth in children. He then observed these restorations for 3 to 58 months before he extracted the restored teeth for orthodontic reasons. Histological assessments of the dental pulps of the extracted teeth were carried out. Results show than more than $90 \%$ (50 out of 55 teeth) had a satisfactory pulpal response. In general, the dental pulp had abundant reparative dentine. A wide odontoblast layer was present beneath the pre-dentine [33].

In general, these studies demonstrate that SDF treatment is a simple and cost-effective method for caries control in children [12,32]. As 38\% SDF has high fluoride concentration (44,800 ppm F), some researchers are concerned about its high fluoride concentration causing dental fluorosis [39]. Although SDF has been used in Australia, Asian countries, such as China and Thailand, and South American countries, such as Brazil and Peru, are concerned that SDF is not yet cleared by the US Food and Drug Administration but is accepted to be used in many European countries and in USA [52]. More well-designed clinical trials on SDF for arresting dental caries are necessary to provide sound and convincing evidence.

\section{Conclusion}

In conclusion, arresting caries treatment with SDF can be a method to prevent caries from progression. Clinical studies have demonstrated that $38 \%$ SDF is effective in arresting ECC. There was no significant complication reported in association with SDF treatment. Black staining of the carious lesions is a disadvantage of SDF treatment. Mild but transient gingival irritation can occur in the gingival margin, but it usually heals spontaneously in two days. Because SDF therapy is painless, simple, and low-cost, it could be widely recommended and promoted as an alternative preventive treatment to conventional invasive caries management, especially among child patients who are too young for conventional dental care or those with special needs, or those with difficulty accessing and affording conventional dental care.

\section{Disclosure}

This work is part of Dr. Marcus HoTak Fung's Ph.D. study. Drs. C H Chu, Edward C. M. Lo and, May C. M. Wong served as supervisors for Dr. Fung's study.

\section{References}

1. Chu CH (2000) Treatment of early childhood caries: a review and case report Gen Dent 48: 142-148.

2. Foster T, Perinpanayagam H, Pfaffenbach A, Certo M (2006) Recurrence of early childhood caries after comprehensive treatment with general anesthesia and follow-up. J Dent Child (Chic) 73: 25-30.

3. Steinberg S (2002) A paradigm shift in the treatment of caries. Gen Dent 50 333-338.

4. Rosenblatt A, Stamford TC, Niederman R (2009) Silver diamine fluoride: a caries "silver-fluoride bullet". J Dent Res 88: 116-125.

5. Wilding RJ, Solomon CS (1996) Arrested caries: a review of the repair potential of the pulp-dentine. J Dent Assoc S Afr 51: 828-833.

6. Nyvad B, ten Cate JM, Fejerskov O (1997) Arrest of root surface caries in situ J Dent Res 76: 1845-1853.

7. ten Cate JM (2001) Remineralization of caries lesions extending into dentin. J Dent Res 80: 1407-1411.

8. Daculsi G, LeGeros RZ, Jean A, Kerebel B (1987) Possible physico-chemical processes in human dentin caries. J Dent Res 66: 1356-1359. 
Citation: Fung MHT, Wong MCM, Lo ECM, Chu CH (2013) Arresting Early Childhood Caries with Silver Diamine Fluoride-A Literature Review. Oral Hyg Health 1: 117. doi: 10.4172/2332-0702.1000117

Page 5 of 5

9. Fusayama T (1979) Two layers of carious dentin; diagnosis and treatment Oper Dent 4: 63-70.

10. Mäkinen KK, Chiego DJ Jr, Allen P, Bennett C, Isotupa KP, et al. (1998) Physical, chemical, and histologic changes in dentin caries lesions of primary teeth induced by regular use of polyol chewing gums. Acta Odontol Scand 56 : 148-156.

11. Schwarz E, Lo EC, Wong MC (1998) Prevention of early childhood caries-results of a fluoride toothpaste demonstration trial on Chinese preschool children after three years. J Public Health Dent 58: 12-18.

12. Chu CH, Lo EC, Lin HC (2002) Effectiveness of silver diamine fluoride and sodium fluoride varnish in arresting dentin caries in Chinese pre-schoo children. J Dent Res 81: 767-770.

13. Zhi QH, Lo EC, Lin HC (2012) Randomized clinical trial on effectiveness of silver diamine fluoride and glass ionomer in arresting dentine caries in preschool children. J Dent 40: 962-967.

14. Yee R, Holmgren C, Mulder J, Lama D, Walker D, et al. (2009) Efficacy of silver diamine fluoride for Arresting Caries Treatment. J Dent Res 88: 644-647.

15. Monse B, Heinrich-Weltzien R, Mulder J, Holmgren C, van Palenstein Helderman WH (2012) Caries preventive efficacy of silver diammine fluoride (SDF) and ART sealants in a school-based daily fluoride tooth brushing program in the Philippines. BMC Oral Health 12: 52.

16. Nyvad B, Fejerskov O (1997) Assessing the stage of caries lesion activity on the basis of clinical and microbiological examination. Community Dent Oral Epidemiol 25: 69-75.

17. Di Nicolo R, Guedes-Pinto AC, Carvalho YR (2000) Histopathology of the pulp of primary molars with active and arrested dentinal caries. J Clin Pediatr Dent 25: $47-49$

18. Eidelman E, Ulmanksy M, Michaeli $Y$ (1992) Histopathology of the pulp in primary incisors with deep dentinal caries. Pediatr Dent 14: 372-375.

19. Yamaga R, Nishino M, Yoshida S, Yokomizo I (1972) Diammine silver fluoride and its clinical application. J Osaka Univ Dent Sch 12: 1-20.

20. Suzuki T, Nishida M, Sobue S, Moriwaki Y (1974) Effects of diammine silver fluoride on tooth enamel. J Osaka Univ Dent Sch 14: 61-72.

21. Mei ML, Chu CH, Lo EC, Samaranayake LP (2013) Fluoride and silver concentrations of silver diammine fluoride solutions for dental use. Int Paediatr Dent 23: 279-285.

22. Mei L, Seneviratne CJ, Chu CH, Lo ECM. (2010) Effects of silver-diamine fluoride on caries-like lesion and cariogenic biofilm.

23. Mei ML, Li QL, Chu CH, Yiu CK, Lo EC (2012) The inhibitory effects of silver diamine fluoride at different concentrations on matrix metalloproteinases. Dent Mater 28: 903-908.

24. Coward JE, Carr HS, Rosenkranz HS (1973) Silver sulfadiazine: effect on the ultrastructure of Pseudomonas aeruginosa. Antimicrob Agents Chemother 3 : 621-624.

25. Bragg PD, Rainnie DJ (1974) The effect of silver ions on the respiratory chain of Escherichia coli. Can J Microbiol 20: 883-889.

26. Russell AD, Hugo WB (1994) Antimicrobial activity and action of silver. Prog Med Chem 31: 351-370.

27. Oppermann RV, Rølla G, Johansen JR, Assev S (1980) Thiol groups and reduced acidogenicity of dental plaque in the presence of metal ions in vivo. Scand J Dent Res 88: 389-396.

28. Wysor MS, Zollinhofer RE (1972) On the mode of action of silver sulfadiazine. Pathol Microbiol (Basel) 38: 296-308.

29. Espinosa-Cristobal LF, Martinez-Castanon GA, Tellez-Dector EJ, Nino-Martinez $\mathrm{N}$, Zavala-Alonso NV, et al. (2013) Adherence inhibition of Streptococcus mutans on dental enamel surface using silver nanoparticles. Mater Sci Eng C Mater Biol Appl, 33: 2197-2202.

30. Knight GM, McIntyre JM, Craig GG, Mulyani, Zilm PS, et al. (2009) Inability

Citation: Fung MHT, Wong MCM, Lo ECM, Chu CH (2013) Arresting Early Childhood Caries with Silver Diamine Fluoride-A Literature Review. Oral Hyg Health 1: 117. doi: 10.4172/2332-0702.1000117 to form a biofilm of Streptococcus mutans on silver fluoride- and potassium iodide-treated demineralized dentin. Quintessence Int 40: 155-161.

31. Mei ML, Chu CH, Low KH, Che CM, Lo EC (2013) Caries arresting effect of silver diamine fluoride on dentine carious lesion with $\mathrm{S}$. mutans and $\mathrm{L}$. acidophilus dual-species cariogenic biofilm. Med Oral Patol Oral Cir Bucal 18 e824-831

32. Llodra JC, Rodriguez A, Ferrer B, Menardia V, Ramos T, et al. (2005) Efficacy of silver diamine fluoride for caries reduction in primary teeth and first permanent molars of schoolchildren: 36-month clinical trial. J Dent Res 84: 721-724.

33. Gotjamanos T (1996) Pulp response in primary teeth with deep residual caries treated with silver fluoride and glass ionomer cement ('atraumatic' technique) Aust Dent J 41: 328-334.

34. Nishino M (1969) [Studies on the topical application of ammoniacal silve fluoride for the arrest of dental caries]. Osaka Daigaku Shigaku Zasshi 14: 1-14.

35. Okuyama T (1974) [On the penetration of diammine silver fluoride into the carious dentin of deciduous teeth (author's transl)]. Shigaku 61: 1048-1071.

36. Dos Santos VE Jr, de Vasconcelos FM, Ribeiro AG, Rosenblatt A (2012) Paradigm shift in the effective treatment of caries in schoolchildren at risk. Int Dent J 62: 47-51.

37. Isaksson M, Bruze M, Björkner B, Niklasson B (1993) Contact allergy to Duraphat. Scand J Dent Res 101: 49-51.

38. Gotjamanos T, Ma P (2000) Potential of 4 per cent silver fluoride to induce fluorosis in rats: clinical implications. Aust Dent J 45: 187-192.

39. Gotjamanos T (1997) Safety issues related to the use of silver fluoride in paediatric dentistry. Aust Dent J 42: 166-168.

40. Gotjamanos T, Afonso F (1997) Unacceptably high levels of fluoride in commercial preparations of silver fluoride. Aust Dent J 42: 52-53.

41. Afonso F, Gotjamanos T (1996) An in vitro study of the distribution of silver and fluoride following application of 40 per cent silver fluoride solution to dentine. Aust Dent J 41: 388-392.

42. Neesham DC (1997) Fluoride concentration in $\mathrm{AgF}$ and dental fluorosis. Aust Dent J 42: 268-269.

43. Gotjamanos T, Orton V (1998) Abnormally high fluoride levels in commercial preparations of 40 per cent silver fluoride solution: contraindications for use in children. Aust Dent J 43: 422-427.

44. Vasquez E, Zegarra G, Chirinos E, Castillo JL, Taves DR, et al. (2012) Short term serum pharmacokinetics of diammine silver fluoride after oral application. BMC Oral Health 12: 60 .

45. Suge T, Kawasaki A, Ishikawa K, Matsuo T, Ebisu S (2006) Effect of ammonium hexafluorosilicate on dentin tubule occlusion for the treatment of dentin hypersensitivity. Am J Dent 19: 248-252.

46. Suge T, Kawasaki A, Ishikawa K, Matsuo T, Ebisu S (2008) Ammonium hexafluorosilicate elicits calcium phosphate precipitation and shows continuous dentin tubule occlusion. Dent Mater 24: 192-198.

47. Li YJ (1984) [Effect of a silver ammonia fluoride solution on the prevention and inhibition of caries]. Zhonghua Kou Qiang Ke Za Zhi 19: 97-100.

48. Lo EC, Chu CH, Lin HC (2001) A community-based caries control program for pre-school children using topical fluorides: 18-month results. J Dent Res 80 : 2071-2074.

49. Tan HP, Lo EC, Dyson JE, Luo Y, Corbet EF (2010) A randomized trial on root caries prevention in elders. J Dent Res 89: 1086-1090.

50. Zhang W, McGrath C, Lo EC, Li JY (2013) Silver diamine fluoride and education to prevent and arrest root caries among community-dwelling elders. Caries Res 47: $284-290$

51. McDonald SP, Sheiham A (1994) A clinical comparison of non-traumatic methods of treating dental caries. Int Dent J 44: 465-470.

52. Chu CH, Lo EC (2008) Promoting caries arrest in children with silver diamine fluoride: a review. Oral Health Prev Dent 6: 315-321. 